\title{
BMJ Open Quantifying the risk of heart disease following acute ischaemic stroke: a meta-analysis of over 50000 participants
}

\author{
Trishna Gunnoo, ${ }^{1}$ Nazeeha Hasan, ${ }^{1}$ Muhammad Saleem Khan, ${ }^{1}$ Julia Slark, ${ }^{2}$ \\ Paul Bentley, ${ }^{1}$ Pankaj Sharma ${ }^{3,4}$
}

To cite: Gunnoo T, Hasan N, Khan MS, et al. Quantifying the risk of heart disease following acute ischaemic stroke: a meta-analysis of over 50000 participants. BMJ Open 2016;6:e009535. doi:10.1136/bmjopen-2015009535

- Prepublication history for this paper is available online To view these files please visit the journal online (http://dx.doi.org/10.1136/ bmjopen-2015-009535).

Received 28 July 2015 Revised 14 December 2015 Accepted 17 December 2015

\section{CrossMark}

${ }^{1}$ Department of Medicine, Imperial College London, London, UK

${ }^{2}$ Faculty of Medical \& Health Sciences, University of Auckland, Auckland, New Zealand

${ }^{3}$ Ashford \& St Peters Hospital, Surrey, UK ${ }^{4}$ Institute of Cardiovascular Research Royal Holloway University of London (ICR2UL), London, UK

Correspondence to Professor Pankaj Sharma; pankaj.sharma@rhul.ac.uk

\section{ABSTRACT}

Objective: Following an acute stroke, there is a high risk of recurrence. However, the leading cause of mortality following a stroke is due to coronary artery disease (CAD) and myocardial infarction (MI) but that risk has not been robustly quantified. We sought to reliably quantify the risk of ischaemic heart disease (IHD) in patients presenting with acute ischaemic stroke (AIS) in the absence of a known cardiac history. Setting: A meta-analysis study. PubMed, MEDLINE, EMBASE and Google Scholar were searched for potential studies up to October 2015. Included studies reported an acute cerebral ischaemic event and followed for CAD or MI within 1 year in patients without known IHD. Using arcsine transformed proportions for meta-analysis, studies were combined using a generic inverse variance random-effects model to calculate the pooled standardised mean difference and $95 \% \mathrm{Cls}$. These were interpreted as the percentage prevalence of CAD or incidence of MI following AIS.

Results: 17 studies with 4869 patients with AIS demonstrated a mean average of asymptomatic CAD in $52 \%$. Anatomical methods of CAD detection revealed a prevalence of asymptomatic $\geq 50 \%$ coronary stenosis in $32 \%(95 \% \mathrm{Cl} 19 \%$ to $47 \%$; $p<0.00001)$. 8 studies with 47229 patients with ischaemic stroke revealed an overall risk of $\mathrm{MI}$ in the year following stroke of $3 \%$ (95\% Cl $1 \%$ to $5 \%$; $p<0.00001)$ despite the absence of any cardiac history.

Conclusions: One-third of patients with ischaemic stroke with no cardiac history have more than $50 \%$ coronary stenosis and $3 \%$ are at risk of developing $\mathrm{MI}$ within a year. Our findings provide a reliable quantitative measure of the risk of IHD following AIS in patients with no cardiac history.

\section{INTRODUCTION}

Cardiovascular disease is the single leading cause of mortality worldwide, ${ }^{1}$ costing the UK economy $£ 19$ billion every year, with the National Health Service in England spending around $£ 6.8$ billion on cardiovascular disease in 2012/2013. ${ }^{2}$ Given our ageing population and global increase in noncommunicable diseases, the burden of heart

\section{Strengths and limitations of this study}

We study the risk of heart disease following a stroke in those patients with no cardiac history. This study is the largest of its kind and, by bringing together multiple data sets, robustly quantifies the risk of heart disease following stroke. As with all meta-analyses, the main limitation of this work relates to publication bias

- Most patients with stroke die of heart disease.

- One in three patients with ischaemic stroke with no cardiac history have more than $50 \%$ coronary stenosis.

- $3 \%$ are at risk of developing myocardial infarction within a year of their stroke.

- Patients with stroke need to be screened for silent heart disease and appropriate and aggressive management of total cardiovascular risk factors is required.

disease and stroke is becoming an ever increasing public health issue. ${ }^{3}$

Atherosclerosis as a systemic process; common risk factors and pathophysiology exists between ischaemic stroke, coronary artery disease (CAD) and myocardial infarction (MI). ${ }^{4}$ Any acute atherosclerotic event increases the risk for another in the same or different vascular bed. ${ }^{5}$ Following an acute ischaemic stroke (AIS), there is a high shortterm risk of recurrence; however, the leading cause of mortality in these patients is MI. ${ }^{467}$

A number of studies have evaluated the relationship between stroke and MI yet show varying results on the rate of subsequent cardiovascular events ${ }^{689}$ with wide discrepancy in the observed prevalence of asymptomatic CAD ranging from $15 \%$ to $80 \%$ following AIS. ${ }^{10}{ }^{11}$ While it is probable that those with an established history of ischaemic heart disease (IHD) will account for the majority of subsequent coronary events following AIS, the true risk of CAD and MI in patients with stroke in the absence of a cardiac history is unclear. 
In an attempt to provide clarity and quantification on this issue, we conducted a systematic review and meta-analysis to determine the prevalence of asymptomatic CAD and incidence of MI in patients with AIS in the absence of previous cardiac disease. To the best of our knowledge, this is the largest such study conducted to date.

\section{METHODS}

\section{Data sources}

A search was performed using electronic databases PubMed, MEDLINE, EMBASE and Google Scholar to identify all relevant published studies up to October 2015. The search strategy included keywords with synonyms and MeSH terms:[stroke] OR[cerebrovascular accident] OR[CVA brain] OR[cerebral infarction] OR [transient ischaemic attack] OR[transient ischemic attack] OR[TIA] OR[Cerebral Infarction] OR[Stroke] OR[Brain Ischemia] OR[Ischemic Attack] OR [Transient], along with[asymptomatic coronary artery disease] OR[asymptomatic CAD]; [asymptomatic coronary heart disease] OR[asymptomatic CHD], along with [subclinical ischaemic heart disease] OR[silent myocardial infarction] OR[silent MI] OR[silent myocardial ischaemia]. Search criteria were limited to humans. All terms were then subjected to interaction with each other with Boolean operators $A N D$ or $O R$. Foreign language literature was included and papers translated where necessary. Manual searches identified additional studies from the references of electronically identified studies.

\section{Study selection}

Studies were selected by TG, NH and JS if they fulfilled the following inclusion criteria: (1) acute onset of stroke or transient ischaemic attack (TIA); (2) lesion confirmed by brain imaging (CT/MRI) or at autopsy; (3) investigations for CAD with acceptable levels of sensitivity and specificity ${ }^{12}$; (4) diagnosis of MI according to criteria of the third universal definition proposed by international expert consensus, ${ }^{13}$ and (5) follow-up data for CAD or MI up to 1 year from stroke onset.

Studies were excluded if: (1) age $<18$ years; (2) haemorrhagic stroke and (3) history of IHD (CAD or MI), unless subgroup data were presented for extraction. Owing to the low specificity of ECG to detect ischaemia, investigations using ECG or exercise ECG alone were excluded, except when in conjunction with another modality of testing such as troponin. ${ }^{14}$ Where duplicate studies were identified, data from the latest data set were used. In an attempt to enhance the quality of our analyses, only studies that recruited a minimum of 50 participants were included for final analysis. Studies with a higher minimum number of participants were more likely to be conducted in a systematic manner with a probably more reliable result. ${ }^{15}$ We used the STROBE ${ }^{16}$ checklist as an initial screen of cohort studies and to extract data, $\operatorname{MOOSE}^{17}$ criteria for the reporting of observational studies and the PRISMA statement to guide our reporting of the meta-analyses. ${ }^{18}$

\section{Data extraction}

Data extraction was undertaken independently by two investigators (TG and JS) and any disagreements were resolved by consensus or by the opinion of a third reviewer. For each selected study, the total population of patients with ischaemic stroke without a history of IHD and the proportion with asymptomatic CAD or MI were extracted. Additional information on study design, method of CAD/ MI diagnosis, as well as baseline characteristics such as mean age, sex, ethnicity and the presence of risk factors for cardiovascular disease, was documented.

\section{Statistical analysis}

Since this was a one-sided investigation without a comparison group, a double arcsine transformation was used for proportion meta-analysis. ${ }^{19}{ }^{20}$ For each study, the proportion of patients with stroke who were positive for asymptomatic CAD or silent MI from the total population of patients was recorded. The proportions $\mathrm{P}$ within the populations were calculated by dividing the number of positive events by the number of patients with stroke without known heart disease.

The standardised mean difference (SMD) and SE for each proportion were then calculated: Standardised mean difference $(\mathrm{SMD})=2 \times \arcsin (\sqrt{ } \mathrm{P})$ and $\mathrm{SE}$ was gen erated by $1 / \sqrt{ } \mathrm{n}$. The results were combined using a generic inverse variance random-effects model (DerSimonian and Laird) to calculate weighted pooled SMD and 95\% CIs using review manager $\mathrm{SMD}=(\mathrm{A}){ }^{21}$ The concluding result was interpreted as the percentage prevalence of CAD or incidence of MI by transforming data back to the original scale to give pooled percentage prevalence: $\%$ prevalence $=\left(\sin \times(\mathrm{A} / 2)^{2}\right) \times 100 .^{22}$

To accurately determine the prevalence of asymptomatic $\mathrm{CAD}$, meta-analysis was restricted to studies reporting more sensitive methods of CAD investigation and significant coronary artery occlusion ( $\geq 50 \%$ stenosis). Tests for heterogeneity and sensitivity analysis were performed by systematically and iteratively removing one study at a time and re-running the model to determine the overall effect size. On the basis of the statistical method used, it was not possible or appropriate to assess for publication bias in this study. ${ }^{20}$

\section{RESULTS}

In total, 1308 records were identified and, following screening for exclusions, a total of 24 studies met our inclusion criteria (figure 1). Seventeen studies with 4869 patients with AIS/TIA investigated for asymptomatic CAD and eight studies with 47229 patients demonstrated risk of MI following ischaemic stroke in those without a cardiac history (table 1). Twenty-three studies recruited patients prospectively. 
Figure 1 Flow diagram of search strategy (CAD, coronary artery disease; MI, myocardial infarction).

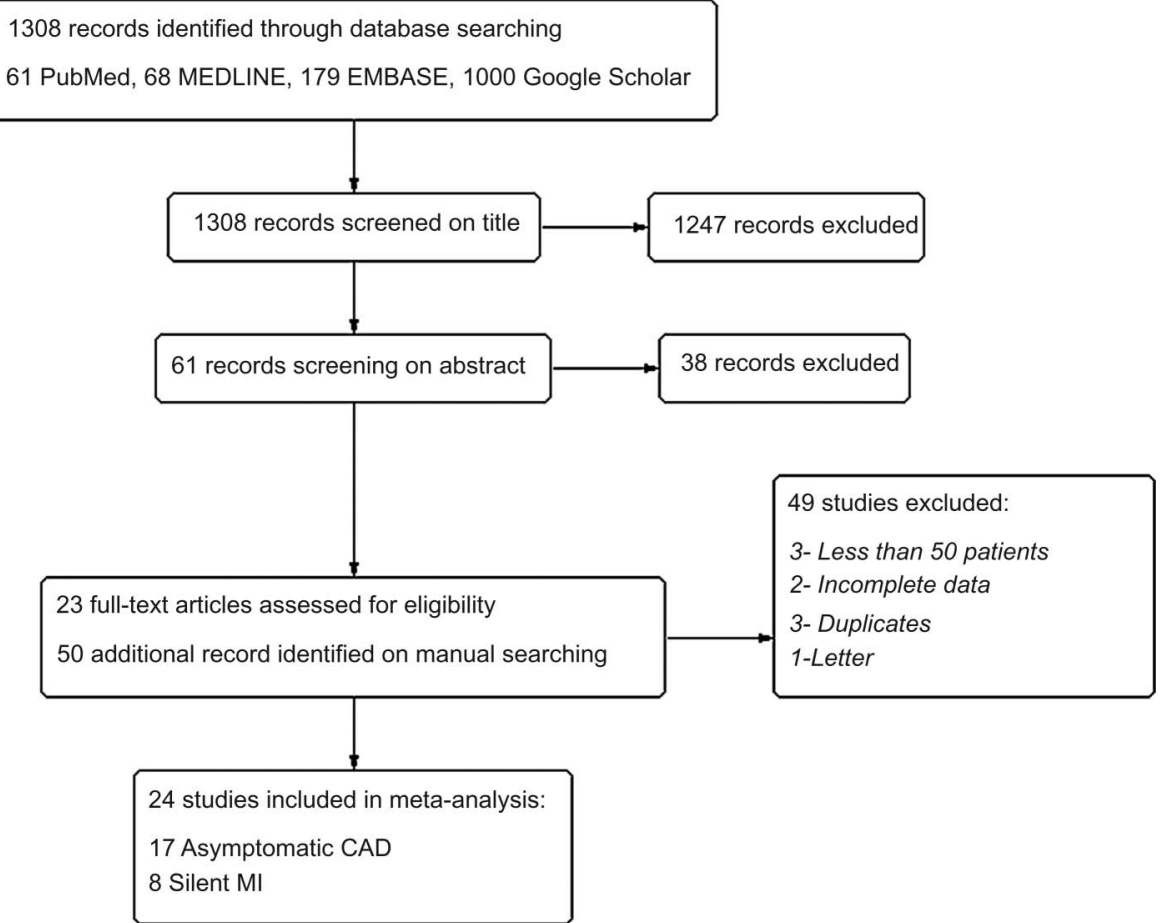

\section{Prevalence of asymptomatic CAD}

There was a similar proportion of males to females in each of the included studies, with an average of $55 \%$ males and a mean age of 66 years. With the exception of a single autopsy study ${ }^{23}$ where the median time between stroke and death was 12 days (IQR 5-32 days), all studies recruited patients with stroke within 10 days. While most studies included ischaemic stroke of atherosclerotic aetiology, three studies excluded cardioembolic stroke ${ }^{5} 1032$ and only one study included those with suspected cardioembolism. ${ }^{29}$ Three studies looked exclusively at first ischaemic stroke. ${ }^{28} 3227$ There were limited data available for the risk factors present in patients found to have asymptomatic CAD; where evaluated, there were varying levels of all risk factors, except hypertension which coexisted in $42-67 \%$ of patients with stroke and was as high as $96 \%$ in one study. ${ }^{24}$ Owing to the variety of methods of investigation with varying levels of sensitivity, and wide range of results, it was not appropriate to perform a meta-analysis on all 17 studies, but the mean average of asymptomatic CAD was $52 \%$.

Meta-analysis was performed on 11 studies using coronary angiography, CT coronary angiography (CTCA), coronary calcium score (CCS) and autopsy as more sensitive investigations for asymptomatic CAD in patients with AIS. This revealed for any degree of coronary plaque a pooled SMD of $1.41(95 \% 1.16$ to 1.66 ; $\left.\mathrm{T}^{2}=0.27 ; \mathrm{I}^{2=99 \%} ; \mathrm{p}<0.00001\right)$ equivalent to a prevalence of $53 \%$ (95\% CI $43 \%$ to $63 \%$ ) (figure 2). A pooled SMD of 1.20 (95\% CI 0.89 to $1.51 ; \mathrm{T}^{2}=0.27 ; \mathrm{I}^{2}=99 \%$; $\mathrm{p}<0.00001$ ) was observed (figure 3), equivalent to a prevalence of $\geq 50 \%$ asymptomatic coronary stenosis of $32 \%(95 \%$ CI $19 \%$ to $47 \%)$. Significant heterogeneity was observed, which was unchanged following iterative analysis, removal of patients with TIA $^{5} 31$ and a unique autopsy study conducted prior to the year 2000.. ${ }^{23}$ Prevalence of any degree of coronary artery stenosis was not statistically significant, most likely due to the high variance in the studies analysed. However, removal of non-Caucasian populations ${ }^{11} 25-31$ yielded a statistically significant pooled SMD of 1.03 (95\% CI 0.88 to 1.17; $\mathrm{p}=0.01$ ), equivalent to an asymptomatic $\mathrm{CAD}$ prevalence of $24 \%$ (95\% CI $18 \%$ to $30 \%$ ).

\section{Incidence of myocardial infarction}

With the exception of one study, ${ }^{39}$ all eight studies prospectively recruited patients with stroke. The majority of studies were based in predominately Caucasian populations from across Europe, Canada and the USA. The largest observational study included a total of 37214 participants from multiple stroke centres across Austria. ${ }^{37}$ For each study, there were similar demographics including a balanced proportion of males to females, with an average of $53 \%$ males and a mean age of 70 years. There were limited data evaluating risk factors in those patients with MI which was diagnosed within 3 months of the AIS and, in most studies in-hospital. A pooled SMD of 0.35 (95\% CI 0.24 to $\left.0.46 ; \mathrm{T}^{2}=0.02 ; \quad \mathrm{I}^{2}=98 \% ; \mathrm{p}<0.00001\right)$ equivalent to a total $\mathrm{MI}$ incidence of $3 \%$ (95\% CI $1 \%$ to $5 \%)$ in patients with stroke with no cardiac history (figure 4).

\section{DISCUSSION}

This study, which quantities the risk of IHD following ischaemic stroke, revealed that over half of such patients with stroke have evidence of asymptomatic coronary 
Table 1 Studies and their characteristics

\begin{tabular}{|c|c|c|c|c|c|c|c|c|c|c|c|}
\hline \multirow[b]{2}{*}{ Study } & \multirow[b]{2}{*}{ Location } & \multirow[b]{2}{*}{$\begin{array}{l}\text { Male } \\
(\%)\end{array}$} & \multirow[b]{2}{*}{$\begin{array}{l}\text { Mean } \\
\text { age }\end{array}$} & \multirow[b]{2}{*}{ Ischaemic event } & \multirow[b]{2}{*}{ Method of investigation } & \multirow[b]{2}{*}{$\mathbf{N}$} & \multicolumn{3}{|c|}{ Asymptomatic CAD } & \multicolumn{2}{|l|}{ MI } \\
\hline & & & & & & & $\mathbf{n}$ & $\begin{array}{l}\text { Per } \\
\text { cent }\end{array}$ & $\begin{array}{l}>50 \% \\
\text { stenosis }\end{array}$ & $\mathbf{n}$ & $\begin{array}{l}\text { Per } \\
\text { cent }\end{array}$ \\
\hline $\begin{array}{l}\text { Gongora-Rivera } \\
\text { et } a l^{23} \text { MASS }\end{array}$ & France & 55 & 60 & Fatal stroke & $\begin{array}{l}\text { Autopsy: plaque, ischaemia, } \\
\text { Ml necrosis/fibrosis }>1 \mathrm{~cm}\end{array}$ & 188 & 131 & 70 & 29 & 59 & 31 \\
\hline $\begin{array}{l}\text { Amarenco et } a l^{24} \\
\text { AMISTAD }\end{array}$ & France & 72 & 62 & Stroke & Coronary angiography & 315 & 195 & 62 & 26 & - & - \\
\hline Ahn et $a$ R5 $^{25}$ & Korea & 65 & 66 & Stroke/TIA & CTCA & 314 & 145 & 46 & 46 & & \\
\hline $\begin{array}{l}\text { Calvet et al, } \\
\text { PRECORIS }\end{array}$ & France & 70 & 63 & Stroke/TIA & CTCA & 274 & 133 & 49 & 18 & - & - \\
\hline Cha et $a^{26}$ & Korea & 64 & 63 & Stroke/TIA & CTCA & 1733 & 1220 & 70 & 33 & & \\
\hline Cho et $a^{27}$ & Korea & 60 & 68 & 1st stroke & CTCA & 274 & 158 & 58 & 22 & - & - \\
\hline Hoshino et $a f^{28}$ & Japan & 72 & 66 & 1st stroke & CTCA & 100 & 36 & 36 & 36 & - & - \\
\hline Iwasaki et al ${ }^{11}$ & Japan & 67 & 63 & Stroke & CCS (calcium score) & 151 & 37 & 25 & 25 & - & - \\
\hline Kim et $a^{P^{9}}$ & Korea & 70 & 67 & Stroke & CTCA & 200 & 161 & 81 & 36 & - & - \\
\hline Seo et $a^{\beta 0}$ & Korea & 63 & 68 & Stroke & CTCA & 71 & 18 & 25 & 25 & - & - \\
\hline Yoon et $a \beta^{\beta 1}$ & Korea & 50 & 71 & Stroke/TIA & CTCA & 175 & 105 & 60 & 21 & - & - \\
\hline Arauz et $a \beta^{\beta 2}$ & Mexico & 69 & 62 & 1st stroke & Stress SPECT & 125 & 40 & 32 & - & - & - \\
\hline Chimowitz et $a \beta^{\beta 3}$ & USA & 64 & 61 & Stroke/TIA & $\begin{array}{l}\text { Stress thallium myocardial } \\
\text { scintigraphy }\end{array}$ & 65 & 23 & 35 & - & - & - \\
\hline Di Pasquale et $a{ }^{\beta 4}$ & Italy & 73 & 56 & $\begin{array}{l}\text { Stroke/TIA of the } \\
\text { carotid system }\end{array}$ & $\begin{array}{l}\text { Exercise thallium myocardial } \\
\text { imaging }\end{array}$ & 140 & 33 & 24 & - & - & - \\
\hline Urbinati et $a{ }^{\beta 5}$ & Italy & 71 & 64 & $\begin{array}{l}\text { Stroke/TIA of the } \\
\text { carotid system }\end{array}$ & $\begin{array}{l}\text { Exercise thallium myocardial } \\
\text { scintigraphy }\end{array}$ & 121 & 28 & 23 & - & - & - \\
\hline Nighoghossian et al ${ }^{10}$ & France & 80 & 59 & Stroke & Stress echo & 60 & 9 & 15 & - & - & - \\
\hline Leys et al, ${ }^{36}$ DETECT & France & 74 & 69 & Stroke & $\mathrm{ECG}+\mathrm{echo}$ & 563 & 64 & 11 & - & - & - \\
\hline Gattringer et $a \beta^{\beta 7}$ & Austria & 53 & 74 & Stroke/TIA & Troponin+ECG & 37214 & - & - & - & 181 & 0.5 \\
\hline Jensen et $a l^{\beta 8}$ & Denmark & 52 & 75 & Stroke & Troponin+ECG & 244 & - & - & - & 7 & 3 \\
\hline Lee et $a \beta^{\beta 9}$ & Korea & 56 & 67 & Stroke & Troponin+ECG & 1247 & - & - & - & 8 & 1 \\
\hline Liao et $a f^{40}$ & Canada & 52 & 72 & Stroke & Troponin+ECG & 7199 & - & - & - & 129 & 2 \\
\hline Mathias et $a l^{41}$ & USA & 52 & 64 & Stroke & Troponin+ECG+echo & 323 & - & - & - & 7 & 2 \\
\hline Prosser et $a l,{ }^{42}$ VISTA & $\begin{array}{l}\text { Canada, Germany, } \\
\text { Sweden, UK, USA }\end{array}$ & 49 & 73 & Stroke & $\begin{array}{l}\text { Cardiac mortality \& serious } \\
\text { cardiac adverse events }\end{array}$ & 458 & - & - & - & 33 & 7 \\
\hline Song et $a f^{43}$ & Korea & 56 & 72 & Stroke & Troponin+ECG & 356 & - & - & - & 0 & 0 \\
\hline
\end{tabular}




\begin{tabular}{|c|c|c|c|c|c|c|c|}
\hline Study or Subgroup & Std. Mean Difference & SE & $\begin{array}{l}+ \\
\text { Total }\end{array}$ & $\begin{array}{l}\mathbf{N} \\
\text { Total }\end{array}$ & Weight & $\begin{array}{l}\text { Std. Mean Difference } \\
\text { IV, Random, } 95 \% \mathrm{Cl}\end{array}$ & $\begin{array}{l}\text { Std. Mean Difference } \\
\text { IV, Random, } 95 \% \mathrm{CI}\end{array}$ \\
\hline Leys 2006 & 0.6878 & 0.0421 & 64 & 563 & $6.0 \%$ & $0.69[0.61,0.77]$ & $=$ \\
\hline Nighoghossian 2006 & 0.7954 & 0.1291 & 9 & 60 & $5.7 \%$ & $0.80[0.54,1.05]$ & $\longrightarrow$ \\
\hline Urbinati 1994 & 1.0037 & 0.0909 & 28 & 121 & $5.9 \%$ & $1.00[0.83,1.18]$ & 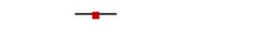 \\
\hline Di Pasquale 1998 & 1.0139 & 0.0845 & 33 & 140 & $5.9 \%$ & $1.01[0.85,1.18]$ & $\varpi$ \\
\hline Iwasaki 2015 & 1.0357 & 0.0814 & 37 & 151 & $5.9 \%$ & $1.04[0.88,1.20]$ & $\varpi$ \\
\hline Seo 2008 & 1.0553 & 0.1187 & 18 & 71 & $5.7 \%$ & $1.06[0.82,1.29]$ & $\longrightarrow$ \\
\hline Arauz 2010 & 1.2025 & 0.0894 & 40 & 125 & $5.9 \%$ & $1.20[1.03,1.38]$ & $\varpi$ \\
\hline Chimowitz 1997 & 1.2742 & 0.124 & 23 & 65 & $5.7 \%$ & $1.27[1.03,1.52]$ & $\longrightarrow$ \\
\hline Hoshino 2008 & 1.287 & 0.1 & 36 & 100 & $5.8 \%$ & $1.29[1.09,1.48]$ & $\varpi$ \\
\hline Ahn 2013 & 1.4943 & 0.0564 & 145 & 314 & $6.0 \%$ & $1.49[1.38,1.60]$ & $\pi$ \\
\hline Calvet 2010 & 1.5416 & 0.0604 & 133 & 274 & $6.0 \%$ & $1.54[1.42,1.66]$ & $\rightarrow$ \\
\hline Cho 2011 & 1.7247 & 0.0604 & 158 & 274 & $6.0 \%$ & $1.72[1.61,1.84]$ & $\pi$ \\
\hline Yoon 2010 & 1.7722 & 0.0756 & 105 & 175 & $5.9 \%$ & $1.77[1.62,1.92]$ & - \\
\hline Amarenco 2011 & 1.8112 & 0.0563 & 195 & 315 & $6.0 \%$ & $1.81[1.70,1.92]$ & 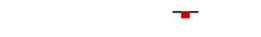 \\
\hline Gongora-Rivera 2007 & 1.9754 & 0.0729 & 131 & 188 & $5.9 \%$ & $1.98[1.83,2.12]$ & 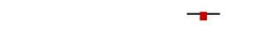 \\
\hline Cha 2013 & 1.991 & 0.024 & 1220 & 1733 & $6.0 \%$ & $1.99[1.94,2.04]$ & $=$ \\
\hline Kim 2011 & 2.2269 & 0.0707 & 161 & 200 & $5.9 \%$ & $2.23[2.09,2.37]$ & $\pi$ \\
\hline Total $(95 \% \mathrm{Cl})$ & & & 2536 & 4869 & $100.0 \%$ & $1.41[1.16,1.66]$ & \\
\hline \multicolumn{7}{|c|}{$\begin{array}{l}\text { Heterogeneity: } \text { Tau }^{2}=0.27 ; \mathrm{Chi}^{2}=1103.54, \mathrm{df}=16(\mathrm{P}<0.00001) ; \mathrm{I}^{2}=99 \% \\
\text { Test for overall effect: } Z=11.11(\mathrm{P}<0.00001)\end{array}$} & SMD \\
\hline
\end{tabular}

Figure 2 Forest plot: prevalence of asymptomatic coronary artery disease after stroke.

plaque and one in three patients have an occlusion of clinical significance ( $>50 \%$ stenosis). Given the strong evidence linking coronary artery stenosis $>50 \%$ to the high risk of acute $\mathrm{MI},{ }^{44} 45$ and our findings that $3 \%$ of patients with ischaemic stroke suffer from MI within 1 year, it is clear that many more individuals with no history of IHD may be at risk of MI than previously appreciated.

Our results are supported by previously published data that demonstrate a high burden of coronary plaque even when there is no previous evidence of systemic disease. The Asymptomatic Myocardial Ischemia in Stroke and Atherosclerotic Disease (AMISTAD) study set out to determine whether asymptomatic coronary atherosclerosis predicts a higher risk of major vascular event in patients with stroke and found that, from a baseline diagnosis of asymptomatic CAD, the 2-year HR of patients with stroke developing $\geq 1$ vessel disease (coronary stenosis $>50 \%$ ) was 3.43 (95\% CI 1.48 to 7.93$){ }^{24}$ In the Multiple Atherosclerosis Site in Stroke (MASS) study, patients with stroke with no atherosclerotic plaque in the cerebral arteries demonstrated prevalence of coronary plaque as high as $51 \% .{ }^{23}$ Thus, despite the limitations in predicting the presence of asymptomatic $\mathrm{CAD}$, based on the detection of extra-cardiac atherosclerosis, an association exists and there is a significant global vascular burden in patients with stroke.

There are limited data to compare our results with the prevalence of subclinical atherosclerosis in an asymptomatic population of similar age. A Norwegian study in 1852 asymptomatic male office workers found that $2.7 \%$ had at least one coronary stenosed artery $\geq 50 \%$ by coronary angiography. ${ }^{46}$ A recent European study with 244 asymptomatic patients undergoing CTCA found a 5\% prevalence of obstructive CAD requiring further investigation. ${ }^{47}$ One larger Korean study with 6311 asymptomatic patients found a prevalence of coronary atherosclerosis $>50 \%$ stenosis in $9 \%$ by CTCA. ${ }^{48}$ Thus, there is considerable difference in cardiac risk between

\begin{tabular}{|c|c|c|c|c|c|c|c|}
\hline Study or Subgroup & Std. Mean Difference & SE & $\stackrel{+}{\text { Total }}$ & $\begin{array}{l}\text { N } \\
\text { Total }\end{array}$ & Weight & $\begin{array}{l}\text { Std. Mean Difference } \\
\text { IV, Random, } 95 \% \mathrm{Cl}\end{array}$ & $\begin{array}{l}\text { Std. Mean Difference } \\
\text { IV, Random, } 95 \% \mathrm{Cl}\end{array}$ \\
\hline Iwasaki 2015 & 1.0357 & 0.0814 & 37 & 151 & $9.0 \%$ & $1.04[0.88,1.20]$ & - \\
\hline Seo 2008 & 1.0553 & 0.1187 & 18 & 71 & $8.4 \%$ & $1.06[0.82,1.29]$ & $\longrightarrow-$ \\
\hline Hoshino 2008 & 1.287 & 0.1 & 36 & 100 & $8.7 \%$ & $1.29[1.09,1.48]$ & 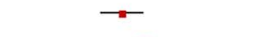 \\
\hline Ahn 2013 & 1.4943 & 0.0564 & 145 & 314 & $9.3 \%$ & $1.49[1.38,1.60]$ & $\rightarrow$ \\
\hline Calvet 2010 & 1.5416 & 0.0604 & 133 & 274 & $9.2 \%$ & $1.54[1.42,1.66]$ & $\pi$ \\
\hline Cho 2011 & 1.7247 & 0.0604 & 158 & 274 & $9.2 \%$ & $1.72[1.61,1.84]$ & $\rightarrow$ \\
\hline Yoon 2010 & 1.7722 & 0.0756 & 105 & 175 & $9.1 \%$ & $1.77[1.62,1.92]$ & $\neg$ \\
\hline Amarenco 2011 & 1.8112 & 0.0563 & 195 & 315 & $9.3 \%$ & $1.81[1.70,1.92]$ & - \\
\hline Gongora-Rivera 2007 & 1.9754 & 0.0729 & 131 & 188 & $9.1 \%$ & $1.98[1.83,2.12]$ & $\rightarrow$ \\
\hline Cha 2013 & 1.991 & 0.024 & 1220 & 1733 & $9.5 \%$ & $1.99[1.94,2.04]$ & - \\
\hline Kim 2011 & 2.2269 & 0.0707 & 161 & 200 & $9.1 \%$ & $2.23[2.09,2.37]$ & - \\
\hline Total $(95 \% \mathrm{Cl})$ & & & 2339 & 3795 & $100.0 \%$ & $1.64[1.44,1.83]$ & \\
\hline \multicolumn{7}{|c|}{$\begin{array}{l}\text { Heterogeneity: } \mathrm{Tau}^{2}=0.10 ; \mathrm{Chi}^{2}=308.38, \mathrm{df}=10(\mathrm{P}<0.00001) ; \mathrm{I}^{2}=97 \% \\
\text { Test for overall effect: } Z=16.42(P<0.00001)\end{array}$} & SMD \\
\hline
\end{tabular}

Figure 3 Forest plot: prevalence of asymptomatic coronary artery disease $>50 \%$ stenosis after stroke. 


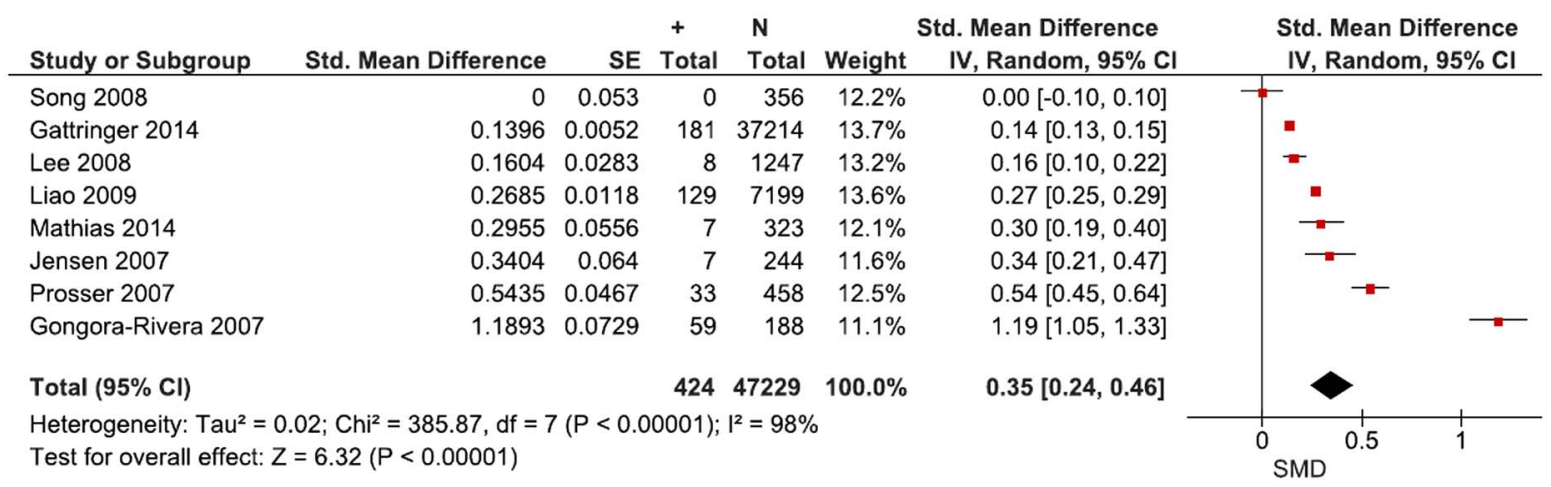

Figure 4 Forest plot: incidence of myocardial infarction after stroke.

the asymptomatic population and patients with stroke, with a prevalence gap from these few studies ranging between $23 \%$ and $29 \%$.

Following a cerebrovascular ischaemic event, patients with no known IHD history the Stroke Prevention by Aggressive Reduction in Cholesterol Levels (SPARCL) trial demonstrated not only the high risk of cardiac events but also supports the benefits of statin therapy in the treatment of stroke when considering this ischaemic event as a coronary risk equivalent. ${ }^{49}$ In determining the beneficial effects of blood pressure reduction, the Perindopril Protection Against Recurrent Stroke Study (PROGRESS) found that $1.2 \%$ of patients with ischaemic stroke went on to have non-fatal MI or death accountable to coronary heart disease (CHD), concluding that secondary prevention should target the cause of the original event as well as mixed vascular risk factors. ${ }^{50}$ The results from an older meta-analysis ${ }^{6}$ calculated a 2.2\% annual risk of MI after ischaemic stroke/TIA, although it failed to estimate the risk of MI according to the cardiac history. Our results support proposals of the American Heart Association and American Stroke Association recommending that patients with stroke be considered for further cardiac evaluation on the basis of their individual cardiovascular risk factor profile. ${ }^{50} 51$

Despite our efforts, no meta-analysis is free from publication bias. A considerable level of heterogeneity in our analyses reflects clinical differences between the studies with inclusion of different subtypes of ischaemic events partly accounting for some of the observed variation. In particular, the different investigations to determine the extent and severity of coronary stenosis (eg, formal coronary angiography, CT angiogram, CCS) may not be equally comparable in terms of their assessment of stenosis. Although we categorise the data by cardiac investigation in table 1 , the overall pooled result is subject to this limitation. To limit the effect of major differences occurring in clinical cardiovascular care, studies prior to the year 2000 were removed. We attempted to improve quality control by incorporating studies with at least 50 participants. These larger studies tend to be better conducted. Study populations located worldwide demonstrated the global burden of asymptomatic disease; however, our results should be extrapolated to other ancestral populations with caution.

We demonstrate that up to a third of patients with ischaemic stroke with no cardiac history have more than $50 \%$ coronary stenosis and $3 \%$ are at risk of developing MI within 1 year following their stroke even in the absence of any previous cardiac symptoms. The cardiac risk posed to patients with ischaemic stroke is substantial even in the absence of an IHD history.

Contributors PS conceived the idea and designed the overall strategy. He critically revised the first and all subsequent drafts and gave final approval to submit. He agrees to be accountable for all aspects of this work. TG, NH and JS undertook the preliminary searches and designed the search criteria. TG wrote the first draft and gave final approval to submit. They both agree to be accountable for all aspects of this work. NH, PB and MS undertook independent statistical analysis of the data with each providing their expert statistical advice. They critically reviewed and revised all manuscript drafts, particularly in relation to the statistical aspects, and all agree to be accountable for all aspects of this work.

Funding PS was, and is, funded by the Department of Health (UK) Senior Fellowships. NH is funded by the MRC.

Competing interests None declared.

Provenance and peer review Not commissioned; externally peer reviewed.

Data sharing statement No additional data are available.

Open Access This is an Open Access article distributed in accordance with the Creative Commons Attribution Non Commercial (CC BY-NC 4.0) license, which permits others to distribute, remix, adapt, build upon this work noncommercially, and license their derivative works on different terms, provided the original work is properly cited and the use is non-commercial. See: http:// creativecommons.org/licenses/by-nc/4.0/

\section{REFERENCES}

1. GBD 2013 Mortality and Causes of Death Collaborator. Global, regional, and national age-sex specific all-cause and cause-specific mortality for 240 causes of death, 1990-2013: a systematic analysis for the Global Burden of Disease Study 2013. Lancet 2015;385:117-71

2. Bhatnagar $P$, Wickramasinghe $\mathrm{K}$, Williams $\mathrm{J}$, et al. The epidemiology of cardiovascular disease in the UK 2014. Heart 2015;101:1182-9.

3. Smith SC. Reducing the Global Burden of Ischemic Heart Disease and Stroke: a challenge for the cardiovascular community and the United Nations. Circulation 2011;124:278-9.

4. Adams RJ, Chimowitz MI, Alpert JS, et al. Coronary risk evaluation in patients with transient ischemic attack and ischemic stroke: a scientific statement for healthcare professionals from the Stroke Council and the Council on Clinical Cardiology of the American Heart Association/American Stroke Association. Stroke 2003;34:2310-22 
5. Calvet D, Touzé E, Varenne O, et al. Prevalence of asymptomatic coronary artery disease in ischemic stroke patients: the PRECORIS study. Circulation 2010;121:1623-9.

6. Touzé E, Varenne O, Chatellier G, et al. Risk of myocardial infarction and vascular death after transient ischemic attack and ischemic stroke: a systematic review and meta-analysis. Stroke 2005;36:2748-55.

7. Dhamoon MS, Elkind MS. Inclusion of stroke as an outcome and risk equivalent in risk scores for primary and secondary prevention of vascular disease. Circulation 2010;121:2071.

8. Burns JD, Rabinstein AA, Roger VL, et al. Incidence and predictors of myocardial infarction after transient ischemic attack: a population-based study. Stroke 2011;42:935-40.

9. Witt BJ, Ballman KV, Brown RD Jr, et al. The incidence of stroke after myocardial infarction: a meta-analysis. Am J Med 2006;119:354.e1-9.

10. Nighoghossian N, Cakmak S, Derex L, et al. Silent coronaropathy: usefulness of dobutamine stress echocardiography in ischemic stroke. Eur Neurol 2006;56:211-16.

11. Iwasaki K, Matsumoto $\mathrm{T}$, Aono $\mathrm{H}$, et al. Prevalence of subclinica atherosclerosis in asymptomatic patients with low-to-intermediate risk by 64 -slice computed tomography. Coron Artery Dis 2011;22:18-25.

12. Al-Shehri H, Small G, Chow B. Cardiac CT, MR, SPECT, ECHO, and PET: what test, when? Appl Radiol 2011;40:13.

13. Thygesen K, Alpert JS, Jaffe AS, et al. Third universal definition of myocardial infarction. Circulation 2012;126:2020-35.

14. Khechinashvili G, Asplund K. Electrocardiographic changes in patients with acute stroke: a systematic review. Cerebrovasc Dis 2002;14:67-76.

15. Button KS, loannidis JP, Mokrysz C, et al. Power failure: why small sample size undermines the reliability of neuroscience. Nat Rev Neurosci 2013;14:365-76.

16. von Elm E, Altman DG, Egger M, et al. The Strengthening the Reporting of Observational Studies in Epidemiology (STROBE) statement: guidelines for reporting observational studies. Lancet 2007:370:1453-7.

17. Stroup DF, Berlin JA, Morton SC, et al. Meta-analysis of observational studies in epidemiology: a proposal for reporting Meta-analysis Of Observational Studies in Epidemiology (MOOSE) group. JAMA 2000;283:2008-12.

18. Moher D, Liberati A, Tetzlaff J, et al. the PRISMA Group. Preferred reporting items for systematic reviews and meta-analyses: the PRISMA statement. Ann Intern Med 2009;151:264-9.

19. Barendregt JJ, Doi SA, Lee YY, et al. Meta-analysis of prevalence. $J$ Epidemiol Community Health 2013;67:974-8.

20. Kulinskaya E, Morganthaler S, Staudte RG. Meta analysis: a guide to calibrating and combining statistical evidence: Wiley series in probability and statistics. 2008. Chapter 18 One-sample binomial tests, p 139

21. Cochrane Collaboration. Review Manager (RevMan).[5.3.5]. Oxford, 2015.

22. The Cochrane Collaboration. 9.2.3.2 The standardised mean difference. In: Higgins J, Green S, eds. Cochrane handbook for systematic reviews of interventions. [version 5.1.0]. Oxford, 2011 http://handbook.cochrane.org/chapter_9/9_2_3_2_the_ standardized mean difference.htm

23. Gongora-Rivera F, Labreuche J, Jaramillo A, et al. Autopsy prevalence of coronary atherosclerosis in patients with fatal stroke. Stroke 2007;38:1203-10.

24. Amarenco P, Lavallée PC, Labreuche J, et al. Prevalence of coronary atherosclerosis in patients with cerebral infarction. Stroke 2011:42:22-9.

25. Ahn SS, Nam HS, Heo JH, et al. Ischemic stroke: measurement of intracranial artery calcifications can improve prediction of asymptomatic coronary artery disease. Radiology 2013;268:842-9.

26. Cha MJ, Lee HS, Kim YD, et al. The association between asymptomatic coronary artery disease and CHADS2 and CHA2 DS2 -VASc scores in patients with stroke. Eur $J$ Neurol 2013;20:1256-63

27. Cho $\mathrm{HJ}$, Lee JH, Kim YJ, et al. Comprehensive evaluation of coronary artery disease and aortic atherosclerosis in acute ischemic stroke patients: usefulness based on Framingham risk score and stroke subtype. Cerebrovasc Dis 2011;31:592-600.

28. Hoshino A, Nakamura T, Enomoto S, et al. Clinical utility of evaluating intracranial artery stenosis and silent brain infarction to predict the presence of subclinical coronary artery disease in ischemic stroke patients. Intern Med 2008;47:1775-0.

29. Kim S, Choe Y, Park SJ, et al. Routine cardiac evaluation in patients with ischaemic stroke and absence of known atrial fibrillation or coronary heart disease: transthoracic echocardiography vs. multidetector cardiac computed tomography. Eur J Neurol 2012;19:317-23.
30. Seo WK, Yong HS, Koh SB, et al. Correlation of coronary artery atherosclerosis with atherosclerosis of the intracranial cerebral artery and the extracranial carotid artery. Eur Neurol 2008;59:292-8.

31. Yoon YE, Chang HJ, Cho I, et al. Incidence of subclinical coronary atherosclerosis in patients with suspected embolic stroke using cardiac computed tomography. Int J Cardiovasc Imaging 2011;27:1035-44.

32. Arauz A, Calleja J, Vallejo E, et al. Prevalence of silent myocardial ischemia in single and multiple lacunar infarcts and large vessel disease stroke. Clin Neurol Neurosurg 2010;112:658-61.

33. Chimowitz MI, Poole RM, Starling MR, et al. Frequency and severity of asymptomatic coronary disease in patients with different causes of stroke. Stroke 1997:28:941-5.

34. Di Pasquale G, Pinelli G, et al. Incidence of silent myocardial ischaemia in patients with cerebral ischaemia. Eur Heart $J$ 1988;9:104.

35. Urbinati S, Di Pasquale G, et al. Preoperative non-invasive coronary risk stratification in candidates for carotid endarterectomy. Stroke 1994;25:2022-7.

36. Leys $\mathrm{D}$, Woimant $\mathrm{F}$, Ferrières $\mathrm{J}$, et al. Detection and management of associated atherothrombotic locations in patients with a recent atherothrombotic ischemic stroke: results of the DETECT survey. Cerebrovasc Dis 2006;21:60-6.

37. Gattringer T, Niederkorn K, Seyfang L, et al. Myocardial infarction as a complication in acute stroke: results from the Austrian stroke unit registry. Cerebrovasc Dis 2014;37:147-52.

38. Jensen JK, Medina H, Nørgaard BL, et al. Association of ischemic stroke to coronary artery disease using computed tomography coronary angiography. Int J Cardiol 2012;160:171-4.

39. Lee SJ, Lee KS, Kim YI, et al. Clinical features of patients with a myocardial infarction during acute management of an ischemic stroke. Neurocrit Care 2008:9:332-7.

40. Liao J, O'Donnell MJ, Silver FL, et al. In-hospital myocardial infarction following acute ischaemic stroke: an observational study. Eur J Neurol 2009;16:1035-40.

41. Mathias TL, Albright KC, Boehme AK, et al. The impact of myocardial infarction vs. pneumonia on outcome in acute ischemic stroke. J Cardiovasc Dis 2014;2:1-3.

42. Prosser J, MacGregor L, Lees KR, et al. Predictors of early cardiac morbidity and mortality after ischemic stroke. Stroke 2007;38:2295-302.

43. Song HS, Back JH, Jin DK, et al. Cardiac troponin T elevation after stroke: relationships between elevated serum troponin $\mathrm{T}$, stroke location, and prognosis. J Clin Neurol 2008;4:75-83.

44. Kallikazaros I, Tsioufis C, Sideris S, et al. Carotid artery disease as a marker for the presence of severe coronary artery disease in patients evaluated for chest pain. Stroke 1999;30:1002-7.

45. Komorovsky R, Desideri A, Coscarelli S, et al. Impact of carotid arterial narrowing on outcomes of patients with acute coronary syndromes. Am J Cardiol 2004;93:1552-5.

46. Thaulow E, Erikssen J, Sandvik L, et al. Initial clinical presentation of cardiac disease in asymptomatic men with silent myocardial ischemia and angiographically documented coronary artery disease (the Oslo Ischemia Study). Am J Cardiol 1993;72:629-33.

47. Bachar GN, Atar E, Fuchs S, et al. Prevalence and clinical predictors of atherosclerotic coronary artery disease in asymptomatic patients undergoing coronary multidetector computed tomography. Coron Artery Dis 2007;18:353-60.

48. Park GM, Yun SC, Cho YR, et al. Prevalence of coronary atherosclerosis in an Asian population: findings from coronary computed tomographic angiography. Int J Cardiovasc Imaging 2015;31:659-68.

49. National Cholesterol Education Program (NCEP) Expert Panel on Detection, Evaluation, and Treatment of High Blood Cholesterol in Adults (Adult Treatment Panel III). Third Report of the National Cholesterol Education Program (NCEP) Expert Panel on Detection, Evaluation, and Treatment of High Blood Cholesterol in Adults (Adult Treatment Panel III) final report. Circulation 2002;106:3143-421.

50. Arima $\mathrm{H}$, Tzourio $\mathrm{C}$, Butcher $\mathrm{K}$, et al. Prior events predict cerebrovascular and coronary outcomes in the PROGRESS trial. Stroke 2006;37:1497-502.

51. Adams HP Jr, del Zoppo G, Alberts MJ, et al Guidelines for the early management of adults with ischemic stroke: a guideline from the American Heart Association/American Stroke Association Stroke Council, Clinical Cardiology Council, Cardiovascular Radiology and Intervention Council, and the Atherosclerotic Peripheral Vascular Disease and Quality of Care Outcomes in Research Interdisciplinary Working Groups: the American Academy of Neurology affirms the value of this guideline as an educational tool for neurologists. Stroke 2007;38:1655-711. 